\title{
The First Annual International Sports Law Journal conference
}

\author{
Johan Lindholm ${ }^{1}$
}

Published online: 13 August 2018

(C) T.M.C. Asser Instituut 2018

The journal's mission is to promote international sports law, a mission that it primarily fulfills by reviewing and disseminating original articles relating to legal aspects of sport and of interest to our global readership. However, international sports law also benefits greatly from sports law researchers and practitioners from around the world meeting to present and discuss high-quality papers. In the spring of 2017, the Editorial Board of the International Sports Law Journal and the Asser International Sports Centre saw a perceived need for an international sports law conference and judging by the overwhelming response to our call for papers, it seems clear that we were correct. The great interest in participating unfortunately meant that we had to make some very difficult decisions and reject some great papers. However, it allowed us to put together excellent panels on six topical, core issues of international sports:

- The FIFA Transfer System

- Labor Rights and Relations in Sports

- Protecting Human Rights in Sports

- The European Union and Sports Governance

- Arbitration in International Sports

- The Operation of the World Anti-Doping System

Close to a hundred individuals from 37 different countries attended the conference which took place on 26-27 October 2017 at the T.M.C. Asser Instituut in The Hague. Besides panel presentations and discussions, the audience was treated to an outstanding set of keynote speakers. Miguel Maduro, the former Chair of the FIFA Governance Committee, identified the resistance to public scrutiny, accountability, and transparency as root causes of the governance crisis currently faced by FIFA and suggested that an independent international agency be established to supervise the governance of international sports governing bodies. In discussion with Sean Cottrell from LawInSport,

Johan Lindholm

johan.lindholm@umu.se

1 Department of Law, Umeå University, 90187 Umeå, Sweden
Michael Beloff, QC, reflected on the development of sport during his exceptional career as a sports lawyer and broad range of current themes in sports law. Stephen Weatherill, Professor of European Law at University of Oxford, examined the conditional autonomy enjoyed by international sports governing bodies under EU law, discussing what he called the "sporting margin of appreciation". Finally, Richard McLaren, Professor of Law at Western University and the former head of WADA's investigation into the Russian doping scandal, spoke about challenges to the operation of the world anti-doping system. This issue of the International Sports Law Journal includes a selection of the papers presented at the conference for the benefit of all those who were not able to attend the event, showcasing the breadth of the conference.

The program for the Second Annual International Sports Law Journal Conference, which will take place on 25-26 October 2018 in The Hague, has already been finalized and features an equally excellent field of contributions as the first conference. The keynote speakers are Margareta Baddeley, a Professor of Law at the Université de Genève and an expert on the interaction between Swiss law and the private regulations of sports-governing bodies, Franck Latty, Professor of Law at the Université Paris Nanterre and the author of a ground-breaking academic study on lex sportiva, and Sylvia Schenk, a German lawyer, CAS arbitrator, and member of FIFA's Human Rights Advisory Board. An additional 18 speakers from around the world will be presenting papers on six contemporary international sports law topics:

- The Governance of Sport in Theory and Practice

- Sports Regulation Between Science, Politics and the Law

- Human Rights in Sports: Window Dressing or New Beginning?

- The Boundaries of Sports Competitions: Competition law and the Private Regulation of Sport

- The Many Faces of Sports Arbitration

- (Re-Re-)Regulating the Football Transfer Market and its Actors 
Given the great interest in last year's event and that the number of seats is limited, we suggest that those who are interested in attending the conference register as soon as possible. $^{1}$
On behalf of the International Sports Law Journal and the Asser International Sports Centre, thanks to all who contributed to the First Annual ISLJ Conference and we hope to see as many of you as possible this fall.

\footnotetext{
${ }^{1}$ For an up-to-date version of the full programme and to register for the conference, please see http://www.asser.nl/sportslawconference/.
} 